\title{
Oxidative Glutamate Toxicity Can Be a Component of the Excitotoxicity Cascade
}

\author{
David Schubert and Dana Piasecki \\ Cellular Neurobiology Laboratory, The Salk Institute for Biological Studies, La Jolla, California 92037
}

\begin{abstract}
Along with ionotropic and metabotropic glutamate receptors, the cystine/glutamate antiporter $\mathrm{x}_{\mathrm{c}}^{-}$may play a critical role in CNS pathology. High levels of extracellular glutamate inhibit the import of cystine, resulting in the depletion of glutathione and a form of cell injury called oxidative glutamate toxicity. Here we show that a portion of the cell death associated with NMDA receptor-initiated excitotoxicity can be caused by oxidative glutamate toxicity. In primary mouse cortical neurons the cell death resulting from the short-term application of $10 \mu \mathrm{m}$ gluta-
\end{abstract}

mate can be divided into NMDA and NMDA receptorindependent phases. The NMDA receptor-independent component is associated with high extracellular glutamate and is inhibited by a variety of reagents that block oxidative glutamate toxicity. These results suggest that oxidative glutamate toxicity toward neurons lacking functional NMDA receptors can be a component of the excitotoxicity-initiated cell death pathway.

Key words: excitotoxicity; brain; death; nerve; non-NMDA; oxidative stress
The physiological consequences of extracellular glutamate are mediated by three classes of membrane proteins within the CNS. These are ionotropic glutamate receptors, metabotropic glutamate receptors, and the cystine/glutamate antiporter. Ionotropic glutamate receptors have two known roles. They are responsible for the majority of excitatory neurotransmission and also for a great deal of CNS pathology. In cases of stroke or trauma, excessive extracellular glutamate leads to nerve cell death via the activation of NMDA receptors (Rothman and Olney, 1986). This phenomenon, which can be reproduced in cell culture (Rothman, 1985; Choi, 1987), is termed excitotoxicity (Olney, 1986). In contrast to ionotropic glutamate receptors, the metabotropic glutamate receptors (mGluRs) are G-protein-coupled membrane proteins with a wide variety of biological functions (Nakanishi, 1994). Finally, a third target for extracellular glutamate in the CNS is the inhibition of the glutamate/cystine antiporter $\mathrm{x}_{\mathrm{c}}^{-}$, which results in a form of oxidative stress and cell death called oxidative glutamate toxicity (Murphy et al., 1989). The glutamate/ cystine antiporter couples the import of cystine to the export of glutamate (Sato et al., 1999). Concentrations of extracellular glutamate as low as $100 \mu \mathrm{M}$, which are well below the level of extracellular glutamate found in models of stroke and trauma (see, for example, McAdoo et al., 1999), completely inhibit the uptake of cystine (Sagara and Schubert, 1998). Cystine is required for the synthesis of the potent intracellular-reducing agent glutathione (GSH). When GSH is depleted by extracellular glutamate, cells die from a form of programmed cell death (Tan et al., 1998a,b).

The potential role of oxidative glutamate toxicity in ischemia and trauma is not understood, but there have been strong indi-

\footnotetext{
Received May 15, 2001; revised June 12, 2001; accepted July 18, 2001.

This work was supported by grants from the National Institutes of Health and Department of Defense Grant DAMD17-99-1-9562. We thank Dr. Pamela Maher for her critical review of this manuscript, Drs. John Donello and Steve Smith for the glutamate assays, and Dr. Rona Giffard for the helpful discussions on cell culture.

Correspondence should be addressed to Dr. David Schubert, The Salk Institute for Biological Studies, 10010 North Torrey Pines Road, La Jolla, CA 92037. E-mail: schubert@salk.edu.

Copyright (ㄷ) 2001 Society for Neuroscience $\quad 0270-6474 / 01 / 217455-08 \$ 15.00 / 0$
}

cations that several cell death pathways are involved. In localized cerebral infarction the neurons in the epicenter die rapidly, whereas those more distal remain viable for several hours (Siesjo, 1992). Multiple forms of nerve cell death also have been identified in excitotoxic CNS primary culture paradigms that follow exposure to glutamate (for review, see Choi, 1992). In primary cultures of cerebellar granule cells that are exposed to glutamate, there is a rapid necrotic phase, followed by delayed apoptotic-like cell death (Ankacrona et al., 1995). During oxygen-glucose deprivation of primary mouse cortical cultures or organotypic cultures of the rat hippocampus, some cell death occurs from ionotropic receptor-independent mechanisms (Gwag et al., 1995; Newell et al., 1995). All of these observations are consistent with in vivo data, which show that glutamate receptor-independent programmed cell death may occur after ischemic insults (Shigeno et al., 1990; Linnik et al., 1993; MacManus et al., 1993; Okamoto et al., 1993). In addition, animals that lack caspases undergo a form of cell death that is morphologically very similar to oxidative glutamate toxicity (Tan et al., 1998a,b; Oppenheim et al., 2001). A number of parameters change dramatically during CNS stress, leading to the observed high exogenous glutamate. These include the direct release of glutamate from cells, the enzymatic conversion of high extracellular glutamine to glutamate, and the shutdown of nerve and glial glutamate uptake systems by pro-oxidant conditions (see Discussion). It is therefore of interest to determine whether oxidative glutamate toxicity can play a significant role in nerve cell death that is associated with the excitotoxicity cascade.

\section{MATERIALS AND METHODS}

Cell culture. Primary cultures of cortical neurons that die reproducibly by excitotoxicity were prepared by combining aspects of two published protocols (Rose et al., 1993; Dugan et al., 1995). Embryonic day 14 (E14) $\mathrm{BALB} / \mathrm{c}$ mouse embryo cortices were minced and treated with $0.1 \%$ trypsin for $20 \mathrm{~min}$. After centrifugation the cells were resuspended in B27 Neurobasal medium (Life Technologies, Grand Island, NY) plus $10 \%$ fetal calf serum and were dissociated by repeated pipetting through a $1 \mathrm{ml}$ blue Eppendorf pipette tip. Then the cells were plated at $1 \times 10^{5}$ cells per well in 96-well poly-L-lysine and laminin-coated microtiter plates (Becton Dickinson, Bedford, MA) in B27 Neurobasal plus 10\% 
fetal calf serum and $20 \%$ glial growth-conditioned medium prepared according to Dugan and colleagues (Dugan et al., 1995). The growthconditioned medium improved plating efficiency by $\sim 30 \%$. Then $2 \mathrm{~d}$ later the medium was aspirated and replaced by serum-free B27 Neurobasal medium plus $10 \mu \mathrm{g} / \mathrm{ml}$ cytosine arabinoside. The cultures were used without media change between 7 and $12 \mathrm{~d}$ after plating and were essentially free of astrocytes (Brewer et al., 1993).

For glutamate toxicity assays, test drugs (e.g., antioxidants) were added 30 min before glutamate exposure. Then the culture medium was moved with a multichannel pipette to a new 96-well plate, and the cells were exposed to glutamate (usually $10 \mu \mathrm{M}$ ) in a HEPES-buffered salt solution [HCSS (Rose et al., 1993)] containing (in mM) $120 \mathrm{NaCl}, 5.4 \mathrm{KCl}, 0.8$ $\mathrm{MgCl}_{2}, 1.8 \mathrm{CaCl}_{2}, 15$ glucose, and $20 \mathrm{HEPES}, \mathrm{pH}$ 7.4. In some cases, 1 $\mu \mathrm{M}$ glycine was included, but this had no net effect on excitotoxic death. After $10 \mathrm{~min}$ at room temperature the HCSS was aspirated, and the original growth medium was returned to the cells. In some cases the NMDA antagonist aminophosphonopentanoic acid (AP-5) was added at this point to inhibit the downstream activation of glutamate receptors.

MTT assay. Cell survival was determined by the MTT [3-(4,5dimethyldiazol-2-yl)-2,5-diphenyl tetrazolium bromide] assay as described (Schubert et al., 1992), which correlates with cell death as determined by trypan blue exclusion and a colony-forming assay (Davis and Maher, 1994). At $24 \mathrm{hr}$ after the addition of glutamate, $10 \mu \mathrm{l}$ of the MTT solution $(2.5 \mathrm{mg} / \mathrm{ml})$ is added to each well and the cells are incubated for $3 \mathrm{hr}$ at $37^{\circ} \mathrm{C}$. Then $100 \mu \mathrm{l}$ of solubilization solution $(50 \%$ dimethylformamide and $20 \%$ SDS, $\mathrm{pH} 4.8$ ) is added to the wells, and the next day the absorption values at $570 \mathrm{~nm}$ are measured. The results are expressed relative to the controls specified in each experiment. They are expressed as the mean of triplet determinations within the same experiment \pm SEM; each experiment has been repeated at least three times with similar results.

Western blotting and glutamate assays. For Western blotting the cells were collected directly in Laemmli buffer (Laemmli, 1970). Cell lysates were resolved in $10 \%$ polyacrylamide gels containing SDS and transferred electrophoretically to hybridization membranes (Micron Separations, Westboro, MA). The membrane was probed first with a rabbit antiserum at a dilution of 1:2000 and then with horseradish peroxidaseconjugated goat anti-rabbit IgG secondary antibody at a dilution of 1:20,000. The antibody conjugates were detected with a chemiluminescence Western blot kit (Amersham, Buckinghamshire, UK).

Glutamate assays in growth-conditioned medium were performed by both mass spectroscopy and standard amino acid analysis with similar results (Iwabuchi et al., 1994). The standard amino acid data are presented. The removal of glutamate from growth-conditioned medium was done exactly as described by Matthews et al.(2000), except that the enzyme was added every $6 \mathrm{hr}$ during the experiment. Media were treated initially for $1 \mathrm{hr}$ at $37^{\circ} \mathrm{C}$ with $100 \mu \mathrm{g} / \mathrm{ml}$ glutamate pyruvate transaminase (GPT), $100 \mu \mathrm{M}$ pyridoxal-L-phosphate and $10 \mathrm{~mm}$ pyruvate; these reagents were left in the culture medium.

Reagents. The mGluR agonists and antagonists were all from Tocris Cookson (Ballwin, MO), and mGluR 1 and 2/3 antisera and anti-NMDA antisera were from Chemicon (Temecula, CA). Anti-mGluR5 was a gift from Dr. R. Gereau (The Salk Institute, La Jolla, CA). The remaining reagents were obtained from Sigma (St. Louis, MO).

\section{RESULTS}

\section{Cortical neuron cell death can be initiated by a purely NMDA receptor-dependent mechanism}

As outlined above, there is some evidence for a non-ionotropic glutamate receptor component of the excitotoxicity cascade, but there have been only limited attempts to isolate and study this event. To do so, a number of criteria should be met. These include reproducibility, a pure nerve cell population to avoid confounding interactions with glia, a quantitative cytotoxic assay, and a system in which the process is initiated by the activation of a single class of ionotropic receptors, ideally NMDA receptors. By combining and modifying a number of published procedures (Rose et al., 1993) (also see, for example, Dugan et al., 1995), we devised a cell culture system that meets these criteria. Briefly, E14 mouse cortical neurons are dissociated and plated into 96-well microtiter plates in Neurobasal medium containing B27 supple-

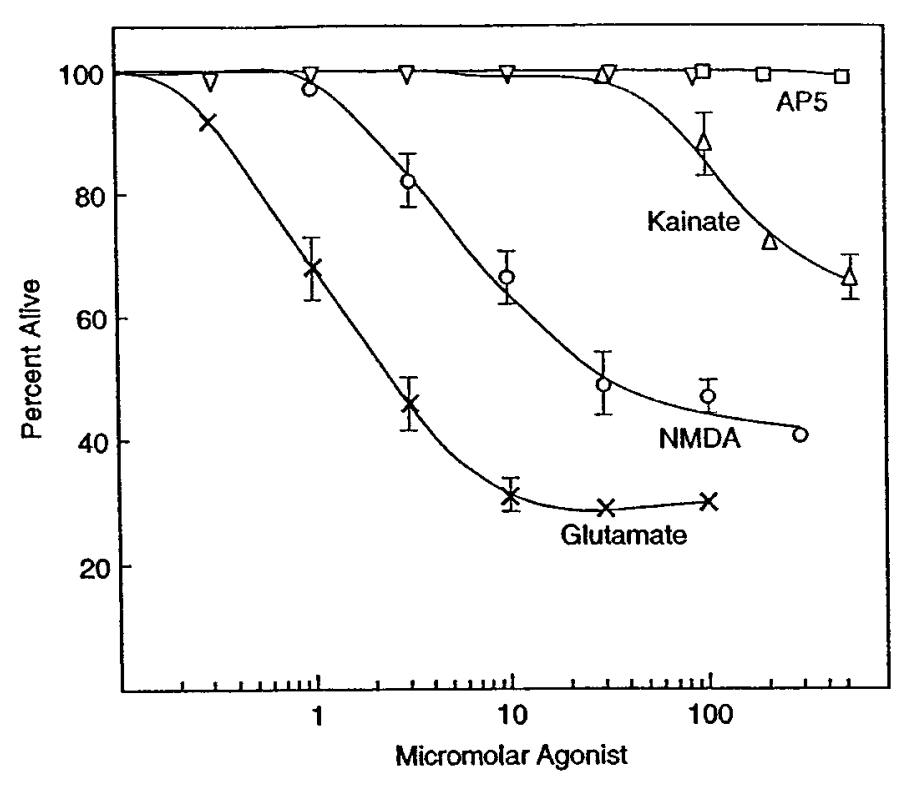

Figure 1. Ionotropic glutamate receptor-mediated toxicity. After $8 \mathrm{~d}$ in culture, E14 cortical neurons were exposed to the indicated reagents for $10 \mathrm{~min}$, and cell viability was measured $24 \mathrm{hr}$ later by the MTT assay, as described in Materials and Methods. The results were confirmed by visual (trypan blue exclusion) assays and are the mean of triplicate determinations \pm SEM. $x$, Glutamate; $\bigcirc$, NMDA; $\triangle$, kainate; $\nabla$, glutamate plus 100 $\mu \mathrm{M}$ AP-5; $\square$, AMPA.

Table 1. Toxicity of $10 \mu \mathrm{M}$ glutamate

\begin{tabular}{llll} 
& \multicolumn{2}{l}{$\mathrm{EC}_{50}$} & \\
\cline { 2 - 4 } Reagent & Day 8 & Day 9 & Day 10 \\
\hline GYKI-52466 & $>100 \mu \mathrm{M}$ & $>100 \mu \mathrm{M}$ & $>100 \mu \mathrm{M}$ \\
AMOA & $>300 \mu \mathrm{M}$ & $>300 \mu \mathrm{M}$ & $>300 \mu \mathrm{M}$ \\
CNQX & $>1000 \mu \mathrm{M}$ & $>1000 \mu \mathrm{M}$ & $>1000 \mu \mathrm{M}$ \\
MK-801 & $500 \mathrm{nM}$ & $450 \mathrm{nM}$ & $450 \mathrm{nM}$ \\
AP5 & $55 \mu \mathrm{M}$ & $50 \mu \mathrm{M}$ & $50 \mu \mathrm{M}$ \\
DCQX & $100 \mu \mathrm{M}$ & $100 \mu \mathrm{M}$ & $100 \mu \mathrm{M}$
\end{tabular}

Cells were exposed to varying concentrations of the reagents for $30 \mathrm{~min}$ before, during, and after exposure to $10 \mu \mathrm{M}$ glutamate for $10 \mathrm{~min}$. Cell death was determined $24 \mathrm{hr}$ later by the MTT assay, and the concentrations that protected $50 \%$ of the cells from $10 \mu \mathrm{M}$ glutamate toxicity are presented. The experiments were repeated at least three times with similar results. The $>$ means that there is no effect at this concentration, the highest tested.

ments (Brewer et al., 1993) and fetal calf serum. Then 2 d later the medium is replaced with serum-free B27-supplemented medium alone containing cytosine arabinoside. The experiments are done between 7 and $14 \mathrm{~d}$ after plating, and cell viability usually is determined by the reduction of MTT (Liu et al., 1997) 24 hr after a $10 \mathrm{~min}$ exposure to glutamate. After $8 \mathrm{~d}$ in culture the cells are killed by glutamate with an $\mathrm{EC}_{50}$ of $\sim 2 \mu \mathrm{M}$ and by NMDA with an $\mathrm{EC}_{50}$ of $20 \mu \mathrm{M}$. AMPA and kainate are not toxic to these cells unless concentrations in excess of $100 \mu \mathrm{M}$ are used (Fig. 1). The toxicity of $10 \mu \mathrm{M}$ glutamate is blocked completely by the NMDA receptor antagonists AP-5, DCQX, and MK-801, but not by the kainate/AMPA antagonists CNQX, GYKI-52466, or AMOA (Table 1). These data show that the cytotoxic cascade in this culture system is initiated exclusively by the activation of NMDA receptors, therefore meeting the criteria for excitotoxicity as initially defined by Olney (1986). 


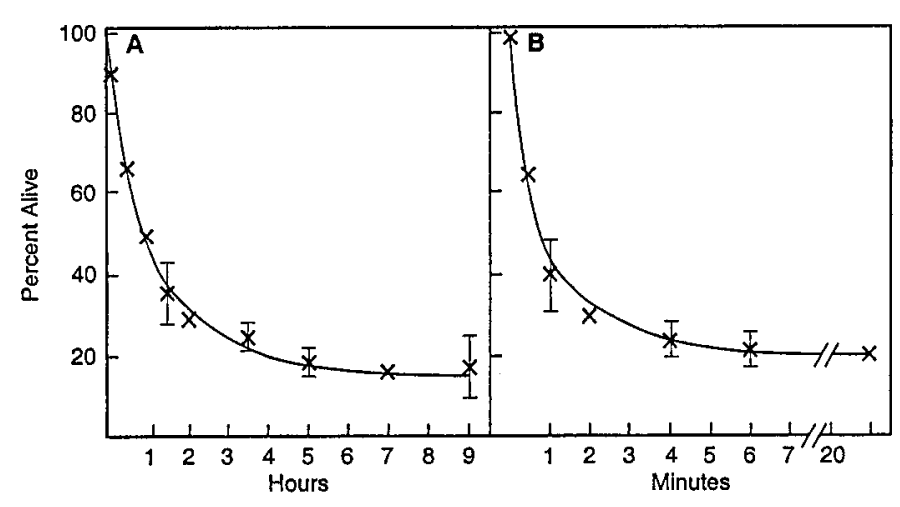

Figure 2. Temporal requirements for glutamate excitotoxicity. A, Cells $9 \mathrm{~d}$ in culture were exposed to $10 \mu \mathrm{M}$ glutamate for $10 \mathrm{~min}$, followed by a $3 \mathrm{hr}$ MTT assay for viability at various times after glutamate exposure. For example, at $0 \mathrm{hr}$ the cells were exposed to glutamate and assayed immediately for viability in the $3 \mathrm{hr}$ MTT assay; the $5 \mathrm{hr}$ point is a $5 \mathrm{hr}$ incubation after glutamate, followed by a $3 \mathrm{hr}$ MTT assay. $B$, Cells were exposed to $10 \mu \mathrm{M}$ glutamate for $0-20 \mathrm{~min}$, followed by the MTT viability assay $24 \mathrm{hr}$ later. At the $30 \mathrm{sec}$ time point $\sim 35 \%$ of the cells died during the next $24 \mathrm{hr}$. The results are the mean of triplicate determinations \pm SEM.

\section{Cell death is initiated rapidly}

To determine how rapidly cells die under the experimental conditions outlined above, we exposed cultures to $10 \mu \mathrm{M}$ glutamate for $10 \mathrm{~min}$, followed by a $3 \mathrm{hr}$ MTT viability assay at various times after glutamate exposure. The results were confirmed by visual assays, including propidium iodide exclusion. Figure $2 A$ shows that most of the cell death is quite rapid, with maximal levels at $\sim 4 \mathrm{hr}$ postglutamate exposure. The duration of exposure to 10 $\mu \mathrm{M}$ glutamate that is required to elicit maximum cell death is also short. When cells are exposed to $10 \mu \mathrm{M}$ glutamate for various lengths of time, followed by a viability assay 24 hr later, cell death is significant after $1 \mathrm{~min}$ and maximum with a 3-4 min exposure (Fig. 2B). All cell death can be prevented by the inclusion of 100 $\mu \mathrm{M}$ AP-5 in the glutamate incubation medium. Therefore, there is a very efficient coupling between NMDA receptor activation and the initiation of the cell death pathways.

\section{Cell death can be divided into three components}

Although the initiation of cell death is totally dependent on the activation of NMDA receptors, it is possible that other forms of cell death are hidden within the ionotropic receptor-initiated process. To isolate a possible NMDA receptor-independent component, we exposed cells to $10 \mu \mathrm{M}$ glutamate for $10 \mathrm{~min}$ and then cultured them continuously in the presence or absence of AP-5, a potent NMDA antagonist that completely blocks glutamate toxicity in these cultures (Table 1). Figure $3 A$ shows that, at $8 \mathrm{~d}$ in culture, three components of the excitotoxicity cascade are revealed by this procedure. Approximately $80 \%$ of the cells are killed by a $10 \mathrm{~min}$ exposure to $10 \mu \mathrm{M}$ glutamate (arrow $A$ ), and none are killed when AP-5 is present with glutamate. However, if AP-5 is added immediately after the exposure to glutamate, $\sim 30 \%$ of the cells are rescued from cell death (arrow B). It follows that the $30 \%$ of the cells that are rescued by AP-5 require NMDA receptor activation after glutamate exposure, whereas the remaining $50 \%$ (arrow $C$ ) must be killed either by the initial exposure to glutamate via the activation of NMDA receptors or by a downstream mechanism that is independent of the NMDA receptor. If AP-5 is present during the exposure to glutamate and then removed from the cultures, there is still no cell death, for under these conditions glutamate cannot activate receptors and initiate the cascade. These observations are consistent with previous observations showing that a significant fraction of cells destined to die after glutamate exposure can be rescued by NMDA antagonists applied after the initial glutamate exposure (Rothman et al., 1987; Hartley and Choi, 1989; Manev et al., 1989). Approximately $20 \%$ of the cells never die under these conditions; the reason for this is unknown.

The interpretation of these data, and the basis for the following experiments, is that the activation of NMDA receptors during the $10 \mathrm{~min}$ exposure to $10 \mu \mathrm{M}$ glutamate initiates the death of a population of cells, which is represented within the " $A$ " and " $C$ " components. This event triggers two additional responses caused by the initial lysis of cells and the accumulation of glutamate in the culture medium. One is the subsequent activation of NMDA receptors on additional cells, resulting in more receptordependent cell death (population B); the other possible outcome is the death of a population of cells that do not have functional NMDA receptors (a subset of population $C$ ). These alternatives are shown schematically in Figure $3 B$, in which the circles on the left represent cells directly killed during the 10 min glutamate exposure and the circles on the right are cells killed after glutamate exposure via NMDA (circled $N$ ) and NMDA receptorindependent (open circles) mechanisms. The experiments below define the cell death pathway by which this latter population is killed.

\section{Glutamate receptor expression changes with length of time in culture}

It has been observed repeatedly that the efficiency of excitotoxic cell death is dependent on the length of time the cells have been maintained in culture (see, for example, Dugan et al., 1995). This is presumably attributable to the time required for the cells to express functional ionotropic receptors. To assay the distribution of NMDA receptor versus non-NMDA receptor-mediated killing as a function of time in culture, we repeated the experiment described in Figure 3 on days 7-11 of cell culture. The fraction of the total nerve cell culture that is killed by a $10 \mathrm{~min}$ exposure to $10 \mu \mathrm{M}$ glutamate increases from $40 \%$ at day 7 to $\sim 80 \%$ on days 10 and 11 (Fig. 4). In contrast, $\sim 60 \%$ of the cells that die are rescued by the postglutamate addition of AP-5 at day 7 . This decreases to $20 \%$ between days 10 and 11 .

The observation that the total number of cells killed increases with culture age suggests that either the level of NMDA receptor expression increases or its coupling to relevant second message systems is dependent on the amount of time the neurons are in culture. Because one NMDA receptor subunit, NR1, is common to most NMDA ionotropic channels (for review, see Akazawa et al., 1994), the expression of this subunit was followed by Western blotting as a function of time in culture. Figure $5 A$ shows that the expression of the NR1 receptor dramatically increases between days 3 and 10 in culture, suggesting that NMDA receptor availability may be limited in the NMDA receptor-mediated killing. Concomitant with culture age is an increase in neurite density (data not shown). Actin is a major component of neurites, and the amount of actin in neuronal cultures correlates with neurite density. Figure $5 A$ shows that there is an increase in actin accumulation closely paralleling that of NR1, suggesting that most of the NR1 may be associated with neurites.

In addition to ionotropic receptors, glutamate activates metabotropic receptors (mGluRs). mGluR activation has been associated with a variety of physiological processes, including protection from oxidative glutamate toxicity (Sagara and Schu- 
Figure 3. A portion of excitotoxic cell death is nonNMDA receptor-mediated. $A$, After $8 \mathrm{~d}$ in culture, E14 cortical neurons were exposed for $10 \mathrm{~min}$ to the indicated concentrations of glutamate in the presence or absence of AP- 5 and then incubated for 24 $\mathrm{hr}$ in the presence or absence of AP-5, at which time cell viability was monitored by the MTT assay. $\mathrm{x}$, Glutamate alone; $\triangle$, glutamate plus $100 \mu \mathrm{M} \mathrm{AP-5}$ during and after the $10 \mathrm{~min}$ glutamate exposure; $\bigcirc$, glutamate plus $100 \mu \mathrm{M}$ AP-5 added immediately after glutamate exposure. $A$ indicates total cell death in the system. $B$ indicates the fraction of cells that die after glutamate exposure by a NMDA receptormediated process. $C$ indicates the fraction of cells that die by virtue of the initial NMDA activation of the cell death pathway plus those that die independently of the NMDA receptor after the initial exposure to glutamate. $B$, Schematic representation of alternative cell death pathways identified above. Open circles represent cells lacking NMDA recep-
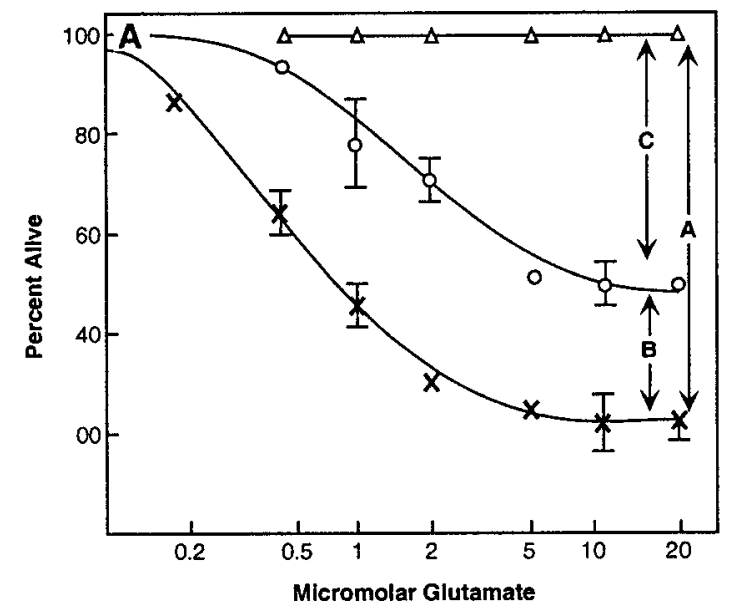

B 10 min. Glutamate After Glutamate Exposure tors and circles enclosing an $N$ represent cells with functional NMDA receptors. The two-headed arrow in $A$ indicates that there may be a reciprocal interaction leading to cell death between cells with and without NMDA receptors.

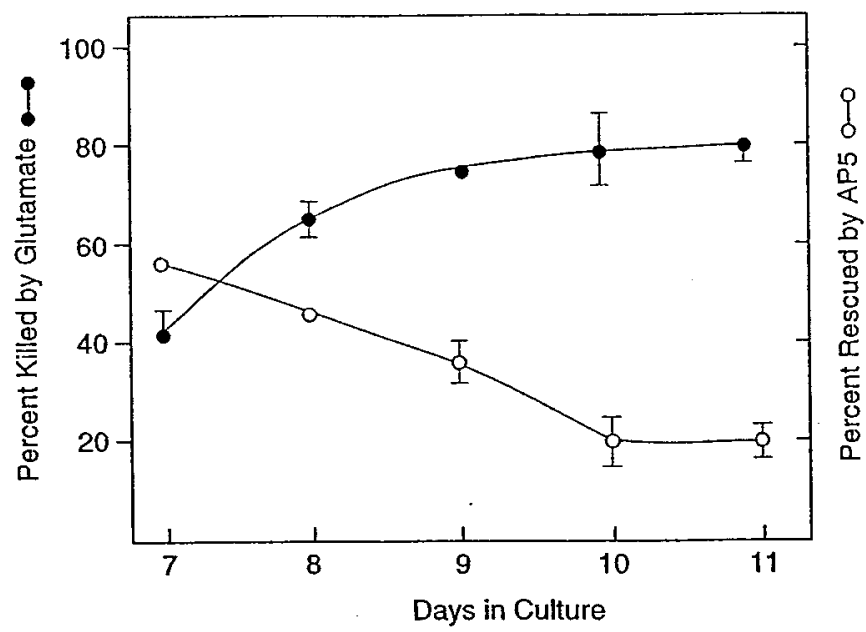

Figure 4. Changes in cell death mechanism as a function of time in culture. E14 cortical cultures were monitored for glutamate-induced cell death exactly as described in Figure 3 but as a function of time in culture. The endpoint that is plotted is the plateau of killing by $10 \mu \mathrm{M}$ glutamate (see Fig. 3). ๑, Percentage of the initial cell population killed by glutamate (10 min exposure); $\bigcirc$, percentage of total late cell death in the culture rescued by AP-5 (see Fig. 3B). The data are the mean \pm SEM of three or four experiments.

bert, 1998). Therefore, the expression of mGluRs 1, 3 and 4, and 5 was monitored by Western blotting in the same lysates as NR1 and actin. Figure 5 shows that all of these receptors are expressed in the cortical cultures but that their expression patterns vary. The expression of mGluRs 1 and 5 increases with time in culture until day 7, after which their expression declines. In contrast, the expression of mGluRs 2 and/or 3 increases with culture age in a manner similar to that of NR1 and actin.

\section{Oxidative glutamate toxicity is a component of excitotoxicity}

Oxidative glutamate toxicity is a well studied programmed cell death pathway that is independent of ionotropic glutamate receptors (Murphy et al., 1989; Maher and Davis, 1996; Li et al., 1997a,b; Tan et al., 1998a,b). If oxidative glutamate toxicity is a component of excitotoxicity, then it should be inhibited by reagents that selectively block oxidative glutamate toxicity, but not by AP-5. If a compound blocks the NMDA-mediated component in addition to oxidative glutamate toxicity, then the whole cascade would be inhibited because its initiation is dependent on NMDA receptor activation. Therefore, to determine whether oxidative glutamate toxicity is involved in the excitotoxicity pathway, a variety of components that inhibit oxidative glutamate toxicity but do not block excitotoxicity were screened for their ability to block the $\mathrm{C}$ fraction of the excitotoxicity cascade (see Fig. 3).

A defining characteristic of oxidative glutamate toxicity is that it is strongly inhibited by many antioxidants, including vitamin $\mathrm{E}$ (Murphy et al., 1989). To determine whether part of the C component shares this trait with oxidative glutamate toxicity, we preincubated 8-d-old cultures of cortical cells for $30 \mathrm{~min}$ with 100 $\mu \mathrm{M} \alpha$-tocopherol, followed by glutamate exposure and a $24 \mathrm{hr}$ incubation with $\alpha$-tocopherol \pm AP-5. Figure $6 A$ shows that part of the $\mathrm{C}$ phase of cell death is blocked by $\alpha$-tocopherol, whereas the viability of the cells exposed to glutamate in the absence of AP-5 is increased by the same amount. This increase in viability is expected in the absence of AP-5, because this condition contains both the NMDA receptor-independent and NMDA receptor-mediated components of glutamate toxicity. Because one-half of the cells survive at day 8 in the presence of $\alpha$-tocopherol and because $\alpha$-tocopherol has no effect on excitotoxicity at days 10 and 11 (data not shown), $\alpha$-tocopherol must not block the NMDA receptor-mediated excitotoxicity component. Although these results are consistent with oxidative glutamate toxicity being a component of the excitotoxicity cascade, a number of other reagents known to inhibit oxidative glutamate toxicity were examined also. These include the group I metabotropic glutamate receptor (mGluR1) agonists and a caspase 1 inhibitor that has been shown previously to block oxidative glutamate toxicity (Tan et al., 1998a,b).

The activation of group I mGluRs protects cells from oxidative glutamate toxicity via the activation of the inositol triphosphate pathway (Sagara and Schubert, 1998). If we use the same logic applied to the experiments with vitamin E, if oxidative glutamate toxicity is a component of excitotoxicity, then mGluR1 agonists should inhibit part of component $\mathrm{C}$ of the cascade. Figure $6, B$ and $C$, shows that two mGluR agonists, $(R, S)$-3,5-dihydroxyphenylglycine (DHPG) and trans-1-amino- $1 S, 3 R$-cyclopentane dicarboxylic acid (ACPD), both protect from excitotoxic-initiated glutamate damage in $8 \mathrm{~d}$ cultures. It also has been shown elsewhere that ACPD has a partial protective effect on NMDA- 
A

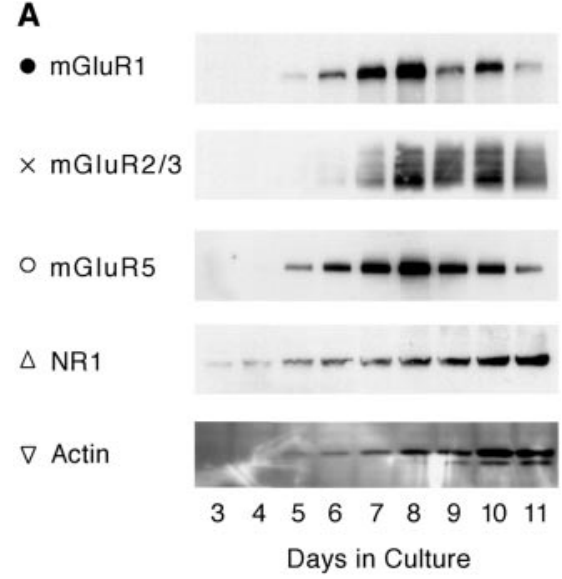

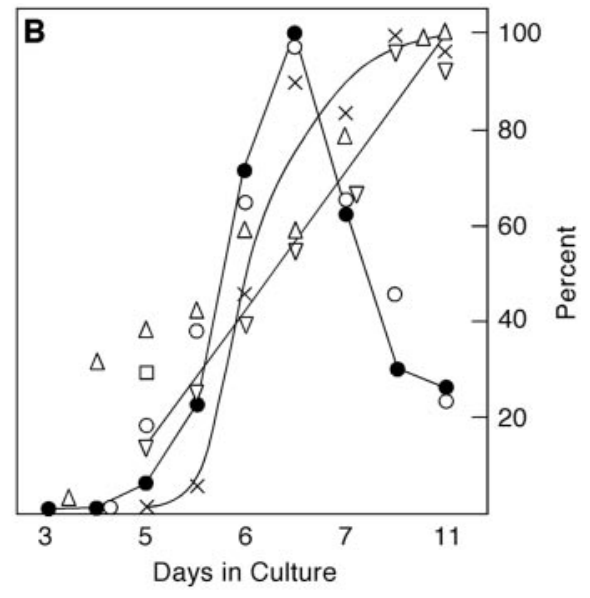

Figure 5. Expression of glutamate receptors as a function of time in culture. Cell lysates were made from E14 cortical neurons cultured for 3-11 d. Then the lysates were run on SDS-acrylamide gels and immunoblotted with the indicated anti-receptor antibodies. The same fraction of each culture dish was loaded per lane; the amount of protein per culture increased only $\sim 20 \%$ from day 7 to 11 . Quantitation was accomplished by scanning the negatives. A, Top, mGluR1; mGluR2/3; mGluR5; NMDA NR1; $A$, Bottom, Actin. The experiments were repeated at least three times with similar results. $B$, Quantitation: - mGluR1; $x$, mGluR2/3;, mGluR5; $\triangle$, $\mathrm{NR} 1 ; \nabla$, actin, shown as a percentage of maximal expression.

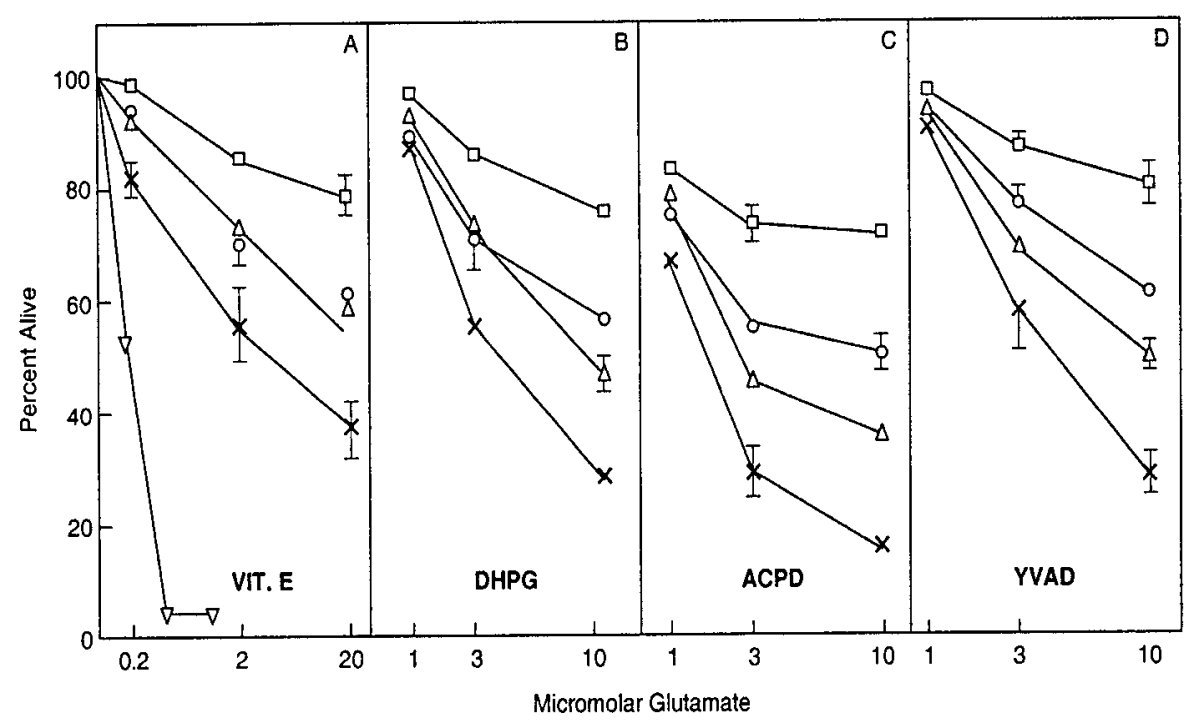

Figure 6. Conditions that block oxidative glutamate toxicity partially protect from excitotoxicinitiated damage. $A, \alpha$-Tocopherol protects from cell death. Cells cultured for $8 \mathrm{~d}$ were pretreated for $30 \mathrm{~min}$ with $100 \mu \mathrm{M} \alpha$-tocopherol (natural), exposed to $10 \mu \mathrm{M}$ glutamate for $10 \mathrm{~min}$, and then returned to the original medium $\pm \mathrm{AP}-5, \pm$ $\alpha$-tocopherol. x, Glutamate alone; $\bigcirc$, glutamate plus $\alpha$-tocopherol; $\triangle$, glutamate plus $100 \mu \mathrm{M}$ AP-5 after glutamate exposure; $\square$, glutamate plus $\alpha$-tocopherol plus AP-5 after glutamate; $\nabla$, cell viability at $24 \mathrm{hr}$ after continuous exposure to glutamate plus $100 \mu \mathrm{M}$ AP-5, $100 \mu \mathrm{M}$ GYKI-25466, and $500 \mu \mathrm{M}$ CNQX. Multiply glutamate concentration by 1000 (e.g., complete killing at $500 \mu \mathrm{M}$ glutamate). $B, C$, Group I mGluR activation is protective. Cells were pretreated for $30 \mathrm{~min}$ with $100 \mu \mathrm{M}$ mGluR agonists DHPG $(B)$ or $\operatorname{ACPD}(C)$, followed by a $10 \mathrm{~min}$ exposure to the indicated concentrations of glutamate. Then the original culture medium was returned to the cells along with the mGluR reagents and, in some cases, $100 \mu \mathrm{M}$ AP-5 to block downstream NMDA receptor activation. Cell viability was determined $24 \mathrm{hr}$ later by the MTT assay. x, Glutamate alone; $\triangle$, glutamate plus agonist; $\bigcirc$, glutamate plus AP-5 after glutamate exposure; $\square$, glutamate plus AP-5 after the added agonist. $D$, A caspase inhibitor Ac-YVAD-cmk protects cells. Cells were exposed to $30 \mu \mathrm{M}$ Ac-YVAD-cmk for 30 min before exposure to $10 \mu \mathrm{M}$ glutamate. In some cases $100 \mu \mathrm{M}$ AP-5 was present throughout. x, Glutamate alone; $\triangle$, glutamate plus caspase inhibitor; $\bigcirc$, glutamate plus AP-5; $\square$, glutamate plus AP-5 after the added caspase inhibitor.

mediated excitotoxicity (Koh et al., 1991). Another agent that protects cortical neurons from oxidative glutamate toxicity is Ac-YVAD-cmk, a potent caspase inhibitor (Tan et al., 1998a,b). Figure $6 D$ shows that this inhibitor protects cells in the presence of AP-5 by $\sim 20 \%$. These data again substantiate the involvement of oxidative glutamate toxicity as the cause of between 20 and $30 \%$ of the cell death in the excitotoxicity cascade.

The vitamin E, the mGluR agonist, and the caspase inhibitor data show that under certain conditions excitotoxicity can be divided into three components, one of which has the characteristics of oxidative glutamate toxicity. In older cultures (10-11 d) only $20 \%$ of the cell death is blocked by the late application of AP-5, and no cell death is blocked by the oxidative glutamate toxicity antagonists described above (see Fig. 4; data not shown). These data show that the oxidative glutamate toxicity component of excitotoxicity is transient in these cultures and strongly support the argument that vitamin E, DHPG, ACPD, and Ac-YVADcmk do not inhibit the NMDA receptor-mediated response. The transient nature of the oxidative glutamate toxicity response may be attributable to the fact that the NMDA receptor-mediated response is more efficient in older cultures because of higher receptor density (see Fig. 5) or the loss of cells that do not express NMDA receptors from the older cultures. This also would result in a larger fraction of the cells being killed by initial glutamate exposure.

\section{Soluble glutamate mediates late cell death}

Because it is likely that the late cell death outlined above is attributable to glutamate, the amount of free glutamate in the culture medium was assayed as a function of time after the addition of $10 \mu \mathrm{M}$ glutamate for $10 \mathrm{~min}$. The amount of free glutamate increased from undetectable levels $(<10 \mu \mathrm{M})$ to $\sim 300$ $\mu \mathrm{M}$ over a period of $9 \mathrm{hr}$ (Fig. $7 E)$. Glutamate $(300 \mu \mathrm{M})$ is sufficient to inhibit extracellular cystine uptake completely, deplete intracellular GSH in clonal nerve cells (Sagara and Schubert, 1998), and kill $>50 \%$ of the cells in this culture system via oxidative glutamate toxicity, as determined by the long-term exposure to glutamate in the presence of high concentrations of NMDA, AMPA, and kainate antagonists (see Fig. 6A, inverted triangles). These data clearly show that extracellular glutamate in these cultures can reach concentrations sufficient to cause damage via the oxidative glutamate toxicity pathway. The inclusion of 100 

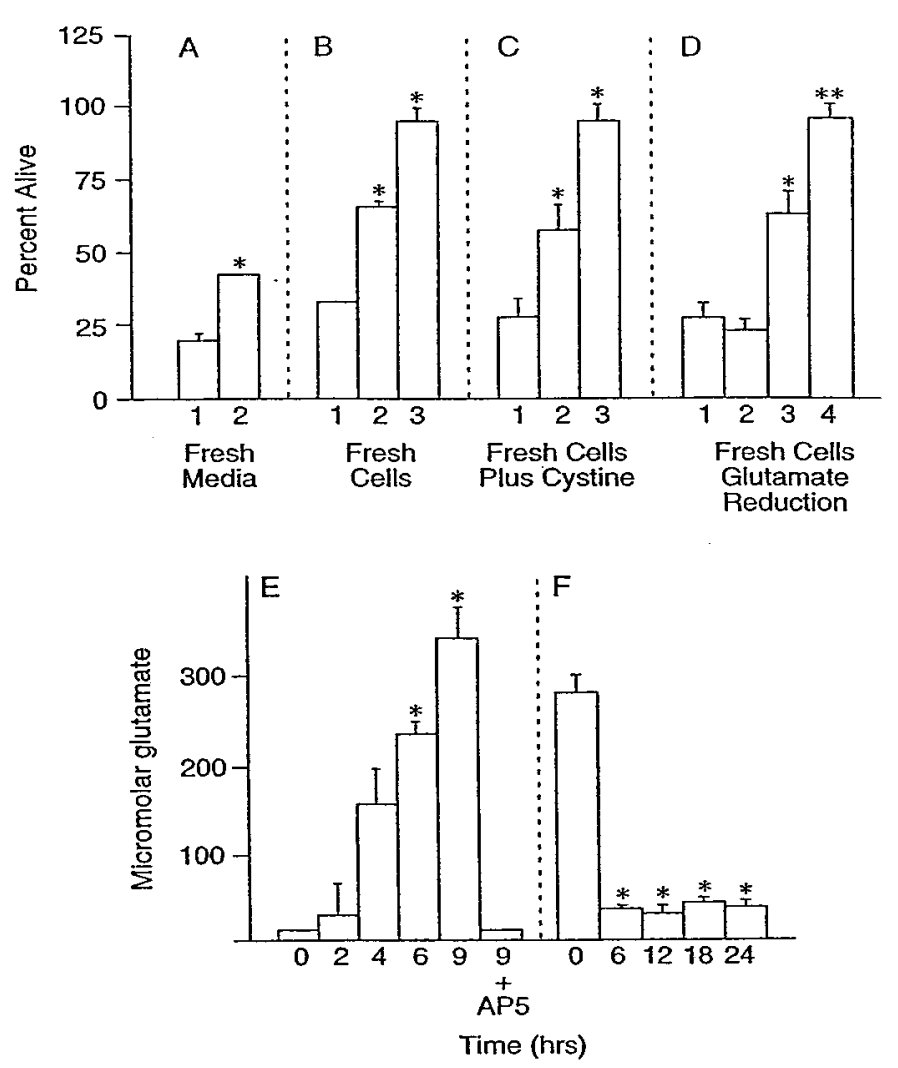

Figure 7. Toxicity is transferred by conditioned medium. Cell viability was measured after $24 \mathrm{hr}$ in all cultures. $A$, Cells cultured for $8 \mathrm{~d}$ were exposed to $10 \mu \mathrm{M}$ glutamate for $10 \mathrm{~min}$, washed once, and returned to their original growth medium. After $11 \mathrm{hr}$ either the cells were given fresh culture medium (2) or the medium was left undisturbed (1). $B$, In another experiment the medium was transferred to new cells of identical age in the absence (1) or presence (2) of $100 \mu \mathrm{M} \mathrm{AP}-5$ or in the presence of AP-5 and $30 \mu \mathrm{M}$ Ac-YVAD-cmk (3). $C$, Cells were exposed to growthconditioned medium alone (1) or in the presence of $2 \mathrm{~mm}$ cystine (2) or in the presence of $2 \mathrm{~mm}$ cystine and $100 \mu \mathrm{M}$ AP-5 (3). Because of the relative insolubility of cystine below $\mathrm{pH} 8$, the experiments with cystine and all controls were performed at $\mathrm{pH} 8$ by the reduction of incubator $\mathrm{CO}_{2}$. D, After $11 \mathrm{hr}$ of glutamate exposure, growth-conditioned media were in some cases $(2,4)$ pretreated for $2 \mathrm{hr}$ with GPT to reduce glutamate and then were transferred to fresh cells. 1, Growth-conditioned medium alone; 2, medium treated with GPT; 3, untreated medium plus AP-5; 4, glutamate-depleted medium plus AP-5. **Bar 4 is significantly different from bar $3, p<0.01 ; n=3$. E, Concentration of glutamate in the growth-conditioned medium as a function of time after the addition of 10 $\mu \mathrm{M}$ glutamate to cultures. In one set of cultures $100 \mu \mathrm{M}$ AP- 5 was added before the addition of $10 \mu \mathrm{M}$ glutamate ( $9 \mathrm{hr}$ plus AP-5). F, Reduction of glutamate in the medium by GPT. GPT and cofactors were added to the growth-conditioned medium before application to the cells initially for 2 $\mathrm{hr}$; then GPT was added repeatedly every $6 \mathrm{hr}$ during the experiment to keep extracellular glutamate below $50 \mu \mathrm{M}$. *Significantly different from control (conditioned medium alone), $p<0.05 ; n=3$.

$\mu \mathrm{M}$ AP-5 during glutamate exposure completely blocked extracellular glutamate accumulation (Fig. $7 E$ ). The glutamate concentrations are higher than previously reported in some cell culture systems (Strijbos et al., 1996), most probably because of the absence of astrocytes to remove free glutamate, but are very similar to those found in the culture media of lysed neurons (Newcomb et al., 1997).

The above data show that there can be an ionotropic receptorindependent component of excitotoxicity, that the latter can be accounted for by the oxidative glutamate pathway, and that there is a high concentration of glutamate in media from lysed cells. If these conclusions are valid, then four additional criteria should be met. (1) Cells previously exposed to glutamate should be protected by replacing their conditioned medium with fresh medium. (2) It should be possible to transfer the late toxicity via the growth-conditioned medium. (3) Elevated exogenous cystine should reverse the inhibition by glutamate and protect cells. (4) The removal of glutamate from the conditioned medium should block downstream oxidative toxicity. Figure $7 A$ shows that conditioned medium replacement with fresh medium after $11 \mathrm{hr}$ reduces subsequent cell death by $\sim 20 \%$ (Fig. $7 A$, bar 2). Figure $7 B$ shows that $\sim 30 \%$ of the cell death caused by the transfer of 11 hr conditioned medium from cells treated for 10 min with $10 \mu \mathrm{M}$ glutamate to fresh cells of the same age is blocked by AP-5 (Fig. $7 B$, bar 2) and that an additional $30 \%$ is blocked by the caspase inhibitor YVAD (Fig. 7B, bar 3).

Because the $\mathrm{x}_{\mathrm{c}}^{-}$antiporter is inhibited by glutamate in a competitive manner (Sato et al., 1999), it should be possible to reverse the effect of exogenous glutamate with cystine. By increasing the concentration of cystine in the culture medium (normally $260 \mu \mathrm{M}$ ) $\sim 10$-fold, we have shown that cells were protected from conditioned medium by $\sim 30 \%$ (Fig. $7 C$, bar 2), with almost complete protection by a combination of cystine and AP-5 (Fig. 7C, bar 3). These data, in conjunction with those presented in Figure 6, strongly suggest that the oxidative glutamate toxicity pathway can kill some of the cells in excitotoxic pathways.

Finally, exogenous glutamate was reduced in the growthconditioned medium by treatment of the medium with $100 \mu \mathrm{g} / \mathrm{ml}$ GPT, $100 \mu \mathrm{M}$ pyridoxal-L-phosphate, and $10 \mathrm{~mm}$ pyruvate (Matthews et al., 2000). Figure $7 F$ shows that GPT treatment reduced glutamate from 300 to $\sim 40 \mu \mathrm{M}$. In the absence of AP-5 there should be a level of cell death caused by reduced glutamate medium similar to conditioned medium alone, because the residual glutamate is sufficient to activate NMDA receptors and all downstream cell death pathways (Fig. 7D, bars 1, 2). In the presence of AP-5, which blocks all NMDA receptor-mediated events, oxidative glutamate toxicity still should occur in the high glutamate medium. However, when extracellular glutamate is reduced to a level at which it can initiate NMDA receptormediated toxicity but not oxidative glutamate toxicity, all of the toxicity should be eliminated in the presence of AP-5. The data in Figure $7 D$ again support a role for oxidative glutamate toxicity, for AP-5 only partially inhibits the cell death in high glutamate medium (Fig. 7D, bar 3), whereas there is $100 \%$ survival in glutamate-depleted medium plus AP-5 (Fig. 7D, bar 4).

\section{DISCUSSION}

The above data show that the excitotoxicity cascade can be divided experimentally into three discrete components, two requiring the activation of NMDA receptors. The initiation of the cell death pathway requires NMDA receptor activation, and a second NMDA receptor-dependent phase takes place after a brief exposure to low concentrations of glutamate. In contrast, a distinct form of cell death can occur after glutamate exposure that is independent of ionotropic glutamate receptors. This pathway, which constitutes $20-30 \%$ of the total cell death in $8-9$ d cultures, has characteristics of oxidative glutamate toxicity, for it is inhibited specifically by vitamin E, by group I metabotropic receptor agonists, by a caspase inhibitor, by elevated extracellular cystine, and by the removal of extracellular glutamate. These data explain earlier observations showing that there is significant cell death in excitatory amino acid toxicity, ischemia, and CNS trauma, which is 
independent of ionotropic glutamate receptors (Meldrum and Garthwaite, 1990) (also see, for example, Choi, 1992).

In cultures of hippocampal neurons, approximately one-half of the cells can be rescued by applying NMDA antagonists after glutamate exposure (Rothman et al., 1987; Hartley and Choi, 1989; Manev et al., 1989). These data and those presented above show that there is an initial population of cells that is killed by glutamate exposure directly and another population that dies later because of the activation of NMDA receptors. The late receptor-mediated cell death could be attributable to either the requirement for a subset of NMDA receptors that respond to the higher concentrations of extracellular glutamate derived from cell lysis or have a requirement for more prolonged exposure to cell-derived glutamate. In our experiments, of the cells that cannot be rescued by the late application of AP-5, approximately one-half die by a process with the characteristics of oxidative glutamate toxicity. The other one-half die because of the initial exposure to glutamate and require NMDA receptor activation.

Previous studies have shown that the activation of different classes of ionotropic glutamate receptors is dependent on glutamate concentration, exposure time, and probably on the cell population. For example, unlike for NMDA, a brief exposure of cortical cells to AMPA and kainate produces little cell death, but exposure of the cells to these receptor agonists for hours produces extensive cell death (Choi et al., 1989; Frandsen et al., 1989). This may be because most AMPA/kainate receptors are relatively impermeable to $\mathrm{Ca}^{2+}$, requiring the activation of voltage-dependent $\mathrm{Ca}^{2+}$ channels for toxicity. In addition to exposure duration, AMPA/kainate receptor-mediated cell death is much slower, requiring many hours for cell lysis to occur (Choi, 1992; Carriedo et al., 1998), and these later forms of cell death have some characteristics of apoptosis (Choi and Rothman, 1990; Kure et al., 1991). However, because AMPA/kainate receptor antagonists have no effect in this culture system (see Table 1), even when added after glutamate exposure (data not shown), it is unlikely that these receptors play a role in the cell death that occurs after transient glutamate exposure. However, consistent with most of the published literature is the observation that some downstream cell death occurs by a mechanism that has many characteristics of programmed cell death, such as caspase activation (Tan et al., 1998a,b). This cell death pathway is oxidative glutamate toxicity.

Oxidative glutamate toxicity requires higher concentrations of glutamate than are necessary for NMDA receptor activation (Murphy et al., 1989). Figure 7 shows that concentrations of extracellular glutamate in the 200-300 $\mu \mathrm{M}$ range are present in cultured cells after initial excitotoxic cell lysis; these concentrations are sufficient to cause oxidative glutamate toxicity (see Fig. $6 A$ ). Similar concentrations of extracellular glutamate have been reported in culture media of lysed neurons (Newcomb et al., 1997) and in CNS trauma models (McAdoo et al., 1999). Because the culture medium contains $2 \mathrm{~mm}$ glutamine and nerve cells possess a very active enzyme, glutaminase, which converts glutamine to glutamate, initial nerve cell lysis releases this enzyme that, in the presence of abundant substrate, leads to an accumulation of glutamate in the culture medium (Newcomb et al., 1997). The brain also contains concentrations of glutamine between 2 and $4 \mathrm{~mm}$, with $0.5 \mathrm{~mm}$ found in CSF (Matsumoto et al., 1996). Because this culture system lacks glial cells and many of the nerve cells are damaged rapidly, there is no effective way of removing glutamate. During ischemia, trauma, and other pro-oxidant conditions there is also likely to be a loss of high-affinity glutamate transporter function because these molecules are exquisitely sensitive to biological oxidants (for review, see Trotti et al., 1998).

In oxidative glutamate toxicity, glutamate blocks the cystine/ glutamate exchange system $\mathrm{x}_{\mathrm{c}}^{-}$, resulting in glutathione depletion and cell death (Murphy et al., 1989). The molecular basis of $x_{c}^{-}$ function has been described recently (Sato et al., 1999). The exchange systems consist of two proteins, the heavy chain of 4F2 (4F2hc) that is involved in several amino acid transport systems and a 502 amino acid protein called XCT. Both XCT and 4F2hc are highly expressed in the brain (Kanai et al., 1998; Sato et al., 1999). Because the cells of the CNS contain sequestered concentrations of free glutamate in the millimolar range (Coyle et al., 1981), as well as the ability to convert glutamine to glutamate, it is probable that any cellular dysfunction, such as loss of energy metabolism or cell lysis, would create local concentrations of glutamate sufficient to inhibit glutamate uptake and subsequent glutathione synthesis in nearby cells. The $\mathrm{EC}_{50}$ glutamate concentration for inhibiting cystine uptake is $<100 \mu \mathrm{M}$ (Sagara and Schubert, 1998), and $\sim 200 \mu \mathrm{M}$ extracellular glutamate kills $50 \%$ of the cortical neurons used in the above experiments via oxidative glutamate toxicity (see Fig. 6A). This sequence of events could lead to cell injury or death in an autocatalytic manner, resulting in a gradient of injury radiating from the site of the initial event. In addition, oxidative glutamate toxicity can generate even greater damage than excitotoxicity, because neurons lacking ionotropic glutamate receptors are killed also. It is therefore of importance to understand how $\mathrm{x}_{\mathrm{c}}^{-}$is regulated in the brain as well as how oxidative glutamate toxicity kills neurons.

\section{REFERENCES}

Akazawa C, Shigemoto R, Bessho Y, Nakanishi S, Mizuno N (1994) Differential expression of five $N$-methyl-D-aspartate receptor subunit mRNAs in the cerebellum of developing and adult rats. J Comp Neurol 347:150-160.

Ankacrona M, Dypbukt JM, Bonfoco E, Zhivotovsky B, Orrenius S, Lipton SA, Nicotera P (1995) Glutamate-induced neuronal death: a succession of necrosis or apoptosis depending on mitochondrial function. Neuron 15:961-973.

Brewer GJ, Torricelli JR, Evege EK, Price PJ (1993) Optimized survival of hippocampal neurons in B27-supplemented Neurobasal, a new serum-free medium combination. J Neurosci Res 35:567-576.

Carriedo SG, Yin HZ, Sensi SL, Weiss JH (1998) Rapid Ca ${ }^{2+}$ entry through $\mathrm{Ca}^{2+}$-permeable AMPA/kainate channels triggers marked intracellular $\mathrm{Ca}^{2+}$ rises and consequent oxygen radical production. J Neurosci 18:7727-7738.

Choi DW (1987) Ionic dependence of glutamate neurotoxicity in cortical cell culture. J Neurosci 7:369-379.

Choi DW (1992) Excitotoxic cell death. J Neurobiol 23:1261-1275.

Choi DW, Rothman SM (1990) The role of glutamate neurotoxicity in hypoxic-ischemic neuronal death. Annu Rev Neurosci 13:171-182.

Choi DW, Viseskul V, Amirthanayagam M, Monyer H (1989) Aspartate neurotoxicity on cultured cortical neurons. J Neurosci Res 23:116-121.

Coyle JT, Bird SJ, Evans RH, Gulley RL, Nadler JV, Nicklas WJ, Olney JW (1981) Excitatory amino acid neurotoxins: selectivity, specificity, and mechanisms of action. Neurosci Res Program Bull 19:331-427.

Davis JB, Maher P (1994) Protein kinase C activation inhibits glutamate-induced cytotoxicity in a neuronal cell line. Brain Res 652:169-173.

Dugan LL, Bruno VMG, Amagasu SM, Giffard RG (1995) Glia modulate the response of murine cortical neurons to excitotoxicity: glia exacerbate AMPA neurotoxicity. J Neurosci 15:4545-4555.

Frandsen A, Drejer J, Schousboe A (1989) Direct evidence that excitotoxicity in cultured neurons is mediated via $N$-methyl-D-aspartate (NMDA) as well as non-NMDA receptors. J Neurochem 53:297-299.

Gwag BJ, Lobner D, Koh JY, Wie MB, Choi DW (1995) Blockade of glutamate receptors unmasks neuronal apoptosis after oxygen-glucose deprivation in vitro. Neuroscience 68:615-619.

Hartley DM, Choi DW (1989) Delayed rescue of $N$-methyl-D-aspartate receptor-mediated neuronal injury in cortical culture. J Pharmacol Exp Ther 250:752-758.

Iwabuchi Y, Kitazawa E, Kobayashi N, Watanabe H, Kanai M, Nakamura K (1994) Studies of drug metabolism using liquid chromatography/ mass spectrometry: comparison of three liquid chromatographic/mass spectrometric interfaces. Biol Mass Spectrom 23:540-546. 
Kanai Y, Segawa H, Miyamoto K, Uchino H, Takeda E, Endou H (1998) Expression cloning and characterization of a transporter for large neutral amino acids activated by the heavy chain of 4F2 antigen. J Biol Chem 273:23629-23632.

Koh J-Y, Palmer E, Cotman CW (1991) Activation of the metabotropic glutamate receptor attenuates $N$-methyl-D-aspartate neurotoxicity in cortical cultures. Proc Natl Acad Sci USA 88:9431-9435.

Kure S, Tominaga T, Yoshimoto T, Tada K, Narisawa K (1991) Glutamate triggers internucleosomal DNA cleavage in neuronal cells. Biochem Biophys Res Commun 179:39-45.

Laemmli UK (1970) Cleavage of structural proteins during the assembly of the head of bacteriophage T4. Nature 227:680-685.

Li Y, Maher P, Schubert D (1997a) A role for 12-lipoxygenase in nerve cell death caused by glutathione depletion. Neuron 19:453-463.

Li Y, Maher P, Schubert D (1997b) Requirement for cGMP in nerve cell death caused by glutathione depletion. J Cell Biol 139:1317-1324.

Linnik MD, Zobrist RH, Hatfield MD (1993) Evidence supporting a role for programmed cell death in focal cerebral ischemia in rats. Stroke 24:2002-2009.

Liu Y, Peterson DA, Kimura H, Schubert D (1997) Mechanism of cellular 3-(4,5-dimethylthiazol-2-yl)-2,5-diphenyltetrazolium bromide (MTT) reduction. J Neurochem 69:581-593.

MacManus JP, Buchan AM, Hill IE, Rasquinha I, Preston E (1993) Global ischemia can cause DNA fragmentation indicative of apoptosis in rat brain. Neurosci Lett 164:89-92.

Maher P, Davis J (1996) The role of monoamine metabolism in oxidative glutamate toxicity. J Neurosci 16:6394-6401.

Manev H, Favaron M, Guidotti A, Costa E (1989) Delayed increase of $\mathrm{Ca}^{2+}$ influx elicited by glutamate: role in neuronal death. Mol Pharmacol 36:106-112.

Matsumoto K, Lo E, Pierce AR, Halpern EF, Newcomb R (1996) Secondary elevation of extracellular neurotransmitter amino acids in the reperfusion phase following focal cerebral ischemia. J Cereb Blood Flow Metab 16:114-124.

Matthews CC, Zielke HR, Wollack JB, Fishman PS (2000) Enzymatic degradation protects neurons from glutamate excitotoxicity. J Neurochem 75:1045-1052.

McAdoo DJ, Xu G-Y, Robak G, Hughes MG (1999) Changes in amino acid concentrations over time and space around an impact injury and their diffusion through the rat spinal cord. Exp Neurol 159:538-544.

Meldrum B, Garthwaite J (1990) Excitatory amino acid neurotoxicity and neurodegenerative disease. Trends Pharmacol Sci 11:379-387.

Murphy TH, Miyamoto M, Sastre A, Schnaar RL, Coyle JT (1989) Glutamate toxicity in a neuronal cell line involves inhibition of cystine transport leading to oxidative stress. Neuron 2:1547-1558.

Nakanishi S (1994) Metabotropic glutamate receptors: synaptic transmission, modulation, and plasticity. Neuron 13:1031-1037.

Newcomb R, Sun X, Taylor L, Curthoys N, Giffard RG (1997) Increased production of extracellular glutamate by the mitochondrial glutaminase following neuronal death. J Biol Chem 272:11276-11282.
Newell D, Barth A, Papermaster V, Malouf AT (1995) Glutamate and nonglutamate receptor-mediated toxicity caused by oxygen and glucose deprivation in organotypic hippocampal cultures. J Neurosci 15:7702-7711.

Okamoto M, Matsumoto M, Ohtsuki T, Taguchi A, Mikoshica K, Yanagihara T, Kamada T (1993) Internucleosomal DNA cleavage involved in ischemia-induced neuronal death. Biochem Biophys Res Commun 196:1356-1362

Olney JW (1986) Inciting excitotoxic cytocide among central neurons In: Advances in experimental medicine and biology (Schwarcz R, Ben-Ari Y, eds), pp 632-645. New York: Plenum.

Oppenheim RW, Flavell RA, Vinsant S, Prevette D, Kuan C-Y, Rakic P (2001) Programmed cell death of developing mammalian neurons after genetic deletion of caspases. J Neurosci 21:4752-4760.

Rose K, Goldberg MP, Choi DW (1993) Cytotoxicity in murine neocortical cell culture. Methods Toxicol 1[A]:46-60.

Rothman SM (1985) The neurotoxicity of excitatory amino acids is produced by passive chloride influx. J Neurosci 5:1483-1489.

Rothman SM, Olney JW (1986) Glutamate and the pathophysiology of hypoxic-ischemic brain damage. Ann Neurol 19:105-111.

Rothman SM, Thurston JH, Hauhart RE (1987) Delayed neurotoxicity of excitatory amino acids in vitro. Neuroscience 22:471-480.

Sagara Y, Schubert D (1998) The activation of metabotropic glutamate receptors protects nerve cells from oxidative stress. J Neurosci 18:6662-6671.

Sato H, Tamba M, Ishii T, Bannai S (1999) Cloning and expression of a plasma membrane cystine/glutamate exchange transporter composed of two distinct proteins. J Biol Chem 274:11455-11458.

Schubert D, Kimura H, Maher P (1992) Growth factors and vitamin E modify neuronal glutamate toxicity. Proc Natl Acad Sci USA 89:8264-8267.

Shigeno T, Yamasaki Y, Kato G, Kusaka K, Mama T, Takakura K, Graham DI, Furukawa S (1990) Reduction of delayed neuronal death by inhibition of protein synthesis. Neurosci Lett 120:117-119.

Siesjo BK (1992) Pathophysiology and treatment of focal cerebral ischemia. I. Pathophysiology. J Neurosurg 77:169-184.

Strijbos PJ, Leach MJ, Garthwaite J (1996) Vicious cycle involving $\mathrm{Na}^{+}$ channels, glutamate release, and NMDA receptors mediates delayed neurodegeneration through nitric oxide formation. J Neurosci 16:5004-5013.

Tan S, Sagara Y, Liu Y, Maher P, Schubert D (1998a) The regulation of peroxide production during programmed cell death. J Cell Biol 141:1423-1432.

Tan S, Wood M, Maher P (1998b) Oxidative stress in nerve cells induces a form of cell death with characteristics of both apoptosis and necrosis. J Neurochem 71:95-105.

Trotti D, Danbolt NC, Volterra A (1998) Glutamate transporters are oxidant-vulnerable: a molecular link between oxidative and excitotoxic neurodegeneration? Trends Pharmacol Sci 19:328-334. 